\title{
An overview of Persian Gulf environmental pollutions
}

\author{
Majid Khazali $^{1 *}$ and Lobat Taghavi ${ }^{2}$ \\ ${ }^{1}$ Department of Energy Engineering and Economy, Faculty of Natural Resources and Environment, Science and Research Branch, \\ Islamic Azad University, Tehran, Iran \\ ${ }^{2}$ Departmet of Environmental Sciences, Faculty of Natural Resources and Environment, Science and Research Branch, Islamic Azad \\ University, Tehran, Iran
}

\begin{abstract}
Aquatic environments are among the most vulnerable habitats that affect all Organisms. The Persian Gulf is home to numerous plant and animal species, and the biological safety is at risk due to its numerous human activities. Traffic of numerous oil and commercial vessels in the area, waste water, desalination, proximity of numerous industrial, refinery and petrochemical units to shores and rivers, oil rigs, fishing, and tourism activities are potential hazards to the environment and should lead to severe chemicals and physicals pollution into the Persian Gulf ecosystem. All this while the Persian Gulf is highly vulnerable due to various natural in the reason of such as low water circulation due to isolation, high evaporation, and low water depth. In this article, previous studies on the status of pollutants in the Persian Gulf have been reviewed. Much of the research on Persian Gulf pollution has focused on hydrocarbons and heavy metals. However, according to recent research, the amounts of these pollutants have been lower than the allowed levels. Also, further research into the impacts of plastics and microplastics on the Persian Gulf ecosystem should be undertaken.
\end{abstract}

\section{Introduction}

The relationship between humans and the environment is very tense, today due to population growth and increasing energy consumption, the extent of damage to nature goes far beyond self-healing and selfpurification. The mentioned damages often could not be repaired and refined even in a small amount by their own. Aquatic environments are among the most vulnerable habitats that affect all Organisms. The Persian Gulf is located in the Middle East and is joined to the sea of Oman through a narrow strait called Hormuz. The existence of such a disjunction in geography limits the rate of species exchange between the regions [1]. The complete replacement of water in this region lasts 3-5 years. As a result, it takes a long time for the Persian Gulf to exterminate pollutants [2]. The Persian Gulf, which is located between the Arabian Peninsula and the Islamic Republic of Iran, and to the Asian Southwest, is an Indian Ocean extension [3]. Seven countries constitute the Arabian Peninsula: Kuwait, Bahrain, Qatar, Saudi Arabia, Yemen, Oman, and United Arab Emirates (UAE). Islamic Republic of Iran, Iraq and six of the above-mentioned countries produce nearly 25 percent of the total oil consumed by the world. With 35 meters average depth (hardly exceeding 100 meters), the Persian Gulf is considered as a rather shallow water body. The Persian Gulf is a semienclosed water body, and the Strait of Hormuz connects it to the global open waters [4-6]. The Gulf hosts some rather susceptible ecosystems related to a naturally highly stressful environment with poor flushing properties, elevated evaporation rates, UV exposure, salinity, and temperatures. Thus, it is more likely that the contaminant materials become subject to slower dispersion, and constrained dilution, and thereby, remain in the region for longer periods of time [7,8]. The integrity of the ecosystem is highly influenced by the activities of humans.

In the Persian Gulf countries, the pollution and contamination of air, soil, and water by inorganic and organic pollutant materials is a key issue. One could attribute the local pollution of the Gulf to extraction of oil from platforms, rapid growth of industrialization, and the traffic of transportation by heavy ships as well as oil spills, although the offshore generated pollution is the second general pollution origin in the same regions followed by discharge of contaminant materials varying from basic or acidic toxins to mercury and the other compounds with organic origin, including Polycyclic Aromatic Hydrocarbons (PAHs) and n-alkanes [2]. At all times, one of the main environmental hazards for human well-being has been marine pollution.

In the Persian Gulf, numerous species are active while they are subject to physiological constraints [4]. Therefore, the extra stresses in the reason of various pollutants to the aquatic environment are of potential extreme outcomes $[7,9,10]$, For example, tanker spills and accidents begin by wars, terminals, land-based urban and industrial sources, offshore oil exploration, and agriculture and recreational development. It is evident that the Persian Gulf seafood such as shrimps and fishes are of high value for earning revenues from exports as well as for being consumed locally. Thus, due

\footnotetext{
* Corresponding author: majid.khazali@s,srbiau.ac.ir
} 
to various socio-economic motivations, keeping the good quality of the aqueous environment is of utmost importance [9,11]. Additionally, since many countries neighboring the Persian Gulf rely on seawater desalination as a drinkable water source for industrial and domestic use, the quality of seawater is extreme importance. Every day, in the Persian Gulf region, a water volume of $14,000,000 \mathrm{~m}^{3}$ is desalinated [12], and after processing, the hot saline wastes are released into the coastal regions which shallow depths. The late modeling attempts have demonstrated that the anticipated desalination capacity growth and the resultant increased discharge of saltwater into the Persian Gulf are of potential significant region-wide effects on the already high salinity and temperatures, leading to increased temperatures of sea ranging from $0.5^{\circ} \mathrm{C}$ to $1.4^{\circ} \mathrm{C}$, and elevated salinity by 10 to 18 Practical Salinity Unit (PSU) at scales pertaining to the whole basin up to 2050 [12].

During the past 30 years, three wars have occurred at the Persian Gulf: the Islamic Republic of Iran- Iraq war (1980-1988), the first and the second Persian Gulf Wars (1991 and 2003, respectively). Thus, a large oil spill occurred in the Persian Gulf in 1991, and as a result, 6 to 8 million Kuwaiti crude oil barrels were discharged into the Persian Gulf in addition to numerous spills due to typical oil operations and those associated with tankers $[7,9,13,14]$. The oil spills occurred due to the first Persian Gulf War is deemed as the worst oil spill throughout history. Thus, a large volume of research was concentrated on the same spill that approved the oil spill impact radius of $400 \mathrm{~km}$ from the point in which the spill occurred to the coastlines of Saudi Arabia and the rapid degradation of the major contaminants [15]. In this paper, previous studies on the types of pollutants in the Persian Gulf have been reviewed, with the aim of identifying major pollutants in the region, the risks and strategies for their prevention and removal.

\section{Methods}

In this review, relevant papers published in past decades regarding Heavy Metals, Polycyclic aromatic hydrocarbons (PAHs) and plastic and micro-plastics pollution in sediments in estuary regions of the Persian Gulf have been discussed. In addition, papers on sedimentary Heavy Metals, PAHs and micro-plastic in core sediments have been collected and analyzed to reveal metal pollution in different historical periods. The review of Heavy Metals, PAHs and plastic pollution in sediments from the Persian Gulf sea will contribute to the comprehensive understanding of the distribution, sources, temporal variability, and ecological risks of pollution in major estuaries and bays of the Persian Gulf sea. The results will help identify potential factors that result in pollution in the aquatic environment and provide references for decision-making on protecting marine ecosystems and public health.

\subsection{Polycyclic Aromatic Hydrocarbon}

PAHs are classified as chemical compounds with semivolatile nature composed of a minimum of two fused rings of benzene in different arrangements, primarily originated from biogenic, pyrogenic, and petro-genic sources [2]. $\Sigma$ LMWs is the sum of the entire 2-3 ring parent-PAHs; however, $\Sigma$ HMWs defines the sum of the entire 4-6 ring parent-PAHs. According to the International Agency of Cancer Research, of the sixteen PAHs categorized as primary high-risk pollutants, some are potential carcinogenic threats for human [16].

In coastal sediments and biota from Qatar, Bahrain, Oman, and UAE, the PAHs and Total Petroleum Hydrocarbons (TPH) were studied [17]. With the exception of the sediments sampled close to the Bahraini oil refinery of the BAPCO, TPH and PAHs were comparatively lower in the studied biota and sediments compared to those of the global reports, including those presented by the United Nations Environment Programme (UNEP), and the National Status and Trends (NS\&T) sites in Alaska.

Additionally, [16] presented a thorough evaluation of the PAHs compositional patterns and distribution and derivatives of them found in tissues of three edible fish species (Scomberomorusguttatus, Lutjanusargentimaculatus, and Lethrinusmicrodon) sampled from the coral reef ecosystems of the Persian Gulf in Iran. The heterogeneous background pollution to PAHs was approved. Also, in fish tissues, the dominance of LMW-PAHs with respect to HMW-PAH compounds was evident. The fish liver showed higher concentrations of PAHs and derivatives of them compared to their muscles, with the lowest and the highest concentrations of PAH found in S. guttatus, and L. argentimaculatus, respectively. In fish tissues, lipid contents and PAHs and also theoctanol-water partition coefficients (Kow) of PAHs congeners showed a significant positive correlation. In addition, there was a high considerable positive correlation between the PAHs levels in the tissues of the fish and their total weight and lengths. Generally, the current findings present valuable basic data for future studies on the PAHs eco-toxicity in aquatic organisms. In fact, in order to find explicit associations between the fish health and their exposure to PAHs, and the resultant implications for the human well-being, it is necessary to conduct more detailed research on both cellular and tissue levels [16].

\subsection{Heavy metals}

Due to their persistence, potential of bioaccumulation and toxicity in numerous species, metals are of greater concern amongst the countless organic and inorganic compounds released into the aqueous environments [18]. Metals could be re-mineralized or absorbed by particles under different biogeochemical cycles if released into marine environments, leading to sub-lethal or even lethal impacts on ecosystems. Considering the diverse physio-chemical processes, such as chelation, precipitation, and adsorption, sediments play the role of scavenger agents, and thus, they act as the secondary contamination source in marine regions with the potential of releasing metals back to the column of water 
in which they become accessible for organisms through desorption, sediment resuspension, and redox reactions. Due to their mobility, toxicity, longer biological halflives, and bioaccumulation via the food chains, the dissolved metals are of a high threatening potential for aquatic, and also, human life. Thus, it is necessary to estimate their levels in marine environments precisely. The metal contamination has had adverse impacts on the health of coral reefs of the Persian Gulf, Iran, due to the coral islands, known as metals sinks, are located adjacent to the sites of petroleum industry [19].

Seafood is considered as a good source of various vitamins, essential fatty acids, minerals, and proteins decreasing heart attack risk and diseases. However, the higher concentration of organic and inorganic contaminants (metalloids and toxic metals) found in seafood has led to concerns on human well-being when consuming them. The seafood contaminated by metals has turned into a critical subject, which is due to their longtime persistence, stability, and nonbiodegradability in food chains. The factors affecting metals bioaccumulation in fish include their ecological requirements, nutritional habits, duration of fish life, metals concentration in sediments and water, physicochemical characteristics of water, and seasonal variations. Amongst heavy metals, arsenic (As), cadmium $(\mathrm{Cd})$, copper $(\mathrm{Cu})$, lead $(\mathrm{Pb})$, and mercury (Hg) are of the greatest potential of being accumulated in fish tissues to concentrations more than the allowed limits. Acute and chronic exposure to such heavy metals mayjeopardize human life. For instance, chronic exposure to lead may lead to gastrointestinal colitis and cerebral diseases, the senses of sight, hearing, and touch may be impaired by mercury, cadmium may lead to cardiovascular diseases and bone pains [20].

The scholars in [20] studied the concentrations for the four metals of arsenic, lead, cadmium and mercury in gill and fillet of Scarusghobban (parrotfish) of the Persian Gulf (Iran). In both gill and fillet, the $\mathrm{Pb}$ concentrations were higher, although the mercury concentrations had the minimum concentrations. The metal concentrations analyzed were much lower than $(p$ $<0.05$ ) the limits recommended by FAO and allowed by national standards. Compared to fillets, the recorded metals accumulation in gills was higher. There was no significant correlation between metals in both gill and fillet ( $p>0.05)$. For both child and adult parrotfish, the values of the Total Target Hazard Quotient (TTHQ) and Target Hazard Quotient (THQ) for fillets were lower than 1 , showing no significant non-carcinogenic risks.

Contrary to expectations, the values of Incremental Lifetime Cancer Risk (ILCR) for children and adults showed that they were of threshold risk of being carcinogenic. Also, the research [20] showed that in Hendijan, Iran, the children were at higher carcinogenic and non-carcinogenic risks than the adults. Thus, in order to protect seafood consumers against health risks, the disposal oflethal toxic metals to aqueous environments must be consistently monitored and controlled [20].

\subsection{Plastics and microplastics}

Over the recent decades, the global plastics production has increased immensely from 1,500,000 tons annually in the 1950 s to $322,000,000$ tons annually in 2015.Also, the plastics are among the most plentiful aquatic wastes found at beaches. Due to the intense and ongoing disposal of plastic-based materials into the environment, their particles are accumulated in aquatic environments and coastlines. Despite the efforts made to cleanse the wastes from the aqueous environments and constraints on disposal along the shorelines and at the seas, the quantity of plastic debris disposal has been increasing so far. This process seems to beinevitable, since most plastics are not degradable biologically, and their amounts found in aqueous environments will increase as the time passes. Ocean currents may also scatter the plastic debris from industrialized and highly populated areas to even the unpopulated and the most distant coastal regions [21].

Dobaradaran et al. [21] researches result demonstrated that given the number of items made of plastic found at the investigated coastlines, the plastic debris found in Bushehr beaches along the Persian Gulf, particularly given the categories of the smaller size ( 5 $\mathrm{mm}$ ), was a great challenge. In spite of the fact that presenting a time schedule to cleanse the Bushehr beach may decrease the amount of plastic debris on the coastline, this process is only useful for the particles of the sizes greater than $5 \mathrm{~cm}$. Due to the dominant inefficient disposals in the Persian Gulf region, the urban managers of the same area are required to resort to more fundamental methods including public training, particularly for people of younger ages through the school capabilities and utilizing media. Given the volume of plastics disposed every year, the same report shows that considerable volumes of metals such as chromium, cadmium, lead, nickel, iron, aluminum, copper and manganese may enter into the aqueous environments annually as well that may create potential acute risks for aqueous organisms, and enter the food chains and ultimately the human bodies. Further studies on transportation, production, the chemical and physical properties, fate, and impacts of Microplastics (MPs) on the Persian Gulf region are highly recommended. One could use the estimation of baseline depicted in this paper as a starting point to reach the necessary data for managing the Persian Gulf region. Ultimately, it is noteworthy to mention that effective removing of microplastic particles from sediments and sand in seawater and coastal areas is not feasible. Thus, the only approach taken to decrease their amounts is reducing the release of plastics into aquatic environments [21].

Additionally, the initial report on the presence of microplastics in shellfishes of the Persian Gulf [22] showed that in the Iranian coastal waters, molluscan shellfish, including deposit feeders, carnivores, and feeders accumulate and ingest MPs in high concentrations among the predatory species, reflecting the MPs trophic transfer within the food web. Most of the discovered plastics were plastics fragments and microfibres that all frequently found everywhere within the aqueous environment as well. Therefore, through 
trophic transfer, shellfish consumers, whether the humans or other animals found in wildlife, could be vulnerable to MPs. The findings of Naji et al. [22] demonstrate that more studies should be conducted on the effect of microplastics on shellfish within the aqueous environment of the Persian Gulf, particularly on those caught adjacent to the highly populated regions to be consumed as a seafood. Given the fact that the environmental circumstances could be changed with the passage of time, establishing long-term and spatial trends in microplastic contamination seems to be essential to determine the vulnerability to the ingestion of microplastics and the high-risk regions for mollusks and other aqueous biotas.

\section{Result and discussion}

The Persian Gulf is known for its unequaled ecosystems, which are vulnerable to the sharing of coasts between various countries, interferences in the reason of human activities and thus, the increasing challenges acting as barriers for conservation attempts and management of the environment. Another feature of the Persian Gulf is the constrained exchange of water with the Indian Ocean, leading to increased potential of catchment and coastal habitat destruction, environmental damages made by pollution, unsustainable utilization of resources, and the loss of biodiversity.

Given the economic activities development, including agriculture, mining, tourism and shrimp aquaculture, population increase and growing desalination, the issues related to Persian Gulf pollution may become worse and lead to considerable public health and ecological risks within the next 20 years. The pollution has already led to changes discovered in mollusks, algal communities, aqueous mammals, and fishes at some sites. The effects of pollution on invaluable coastal habitats (wetlands, lagoons, and estuaries) and the fisheries of Persian Gulf should be particularly investigated due to compared to marginal seas, they have been poorly investigated. The effect of mercury, arsenic, POPs, and contaminants of great concern, including Polybrominated Diphenyl Ethers (PBDEs) and the compounds derived from plastics should be particularly investigated.

The same review has evidently referred to the fact that the pollution to petroleum hydrocarbons, trace elements, and the heavy metals in the marine and coastal regions of Persian Gulf constitute the most research in the area compared to those related to air and soil

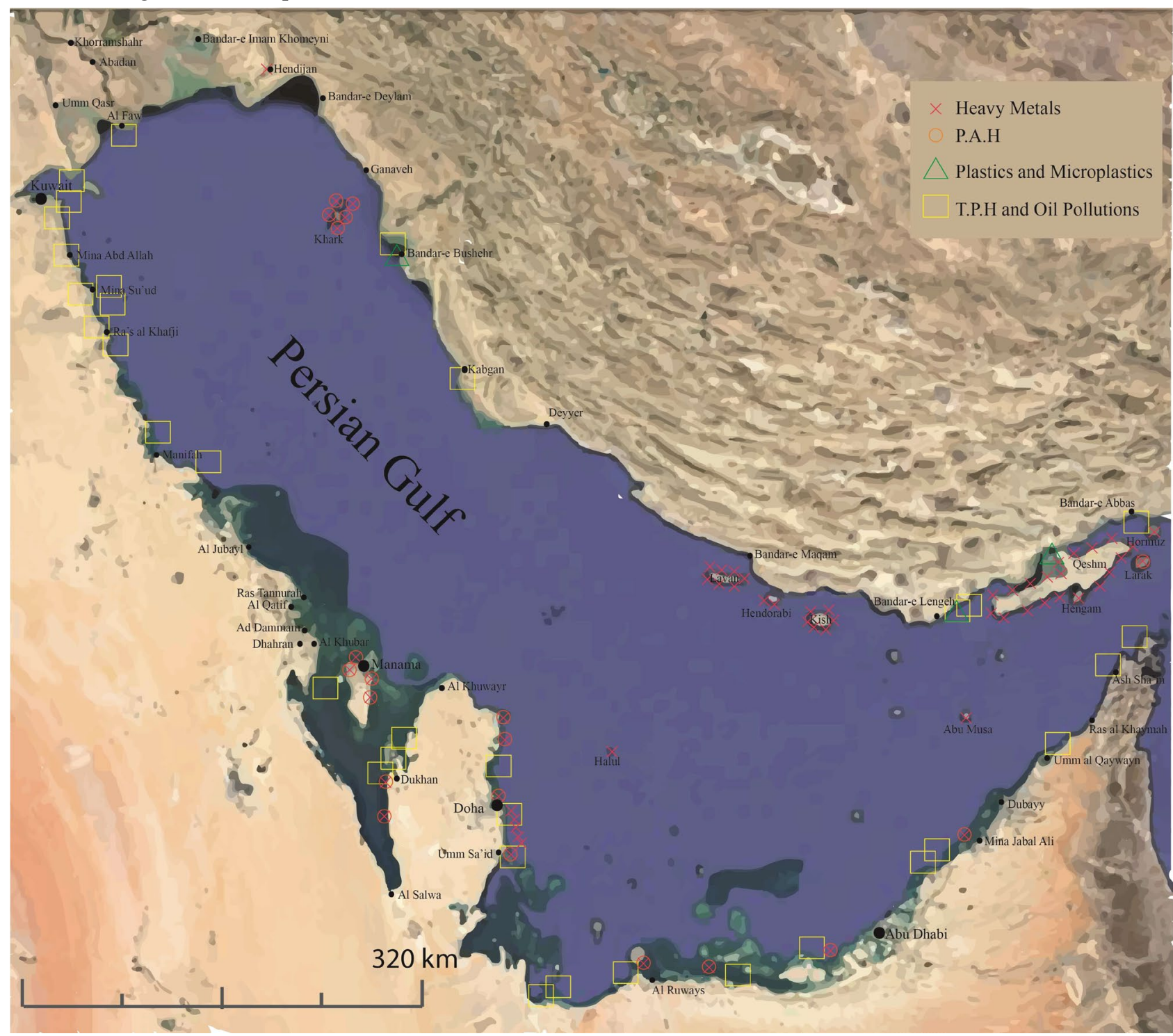

Fig. 1. Locations of sampling of various pollutants in the Persian Gulf. 
pollutions. In addition, less attention has been paid to thermal pollution, increased salinity and other dangers of Persian Gulf water desalination. Contrary to the fact that the contamination to hydrocarbons and metals has imposed significant environmental stresses to the Persian Gulf, and it has experienced three wars over the late 30 years, most of the research considered in this paper showed comparatively low levels contaminations to petroleum residues and heavy metals in various organisms and habitats, and that significant improvements have been made in the region regarding the petroleum hydrocarbon concentrations that have reached their baseline levels before the oil spills in 1991 . Generally, there are few research that have indicated higher concentrations of some pollutions such as comparatively low to moderate chronic contaminations in the reason of metals and oil in some regions, although the chronically contaminated regions were constrained to some hot spots, including the BAPCO site within Bahrain. However, the protective attempts and efficient sustainable management of marine, coastal, air, and soil environments within the Persian Gulf region are very important and crucial for efficient management of resources and deciding on environmental issues.

Figure 1 shows the location of Researches samples studied in this paper. As it turns out, more research has been done on heavy metal contamination and PAHs on the north coast of the Persian Gulf, while on the south coast, most research has focused on Total petroleum hydrocarbon (T.P.H) and oil pollutants. As mentioned, most research in the field of oil pollutants is related to previous years, and in recent years, most research has focused on heavy metals, PAHs and microplastics.

The restoration expenditures are dramatic, and often exceeding the capacities of developing countries. Thus, the initial stage and the crucial objective of effective and efficient management and conservation of the Persian Gulf are protecting it against pollution. The strategies used for the protection of the region will be dependent on regional curative and preventive conventions, strategic action plans for sustainable conservation and use of the resources of the region by complying with the regulations of international entities including the United Nation Development Program (UNDP), and the UNEP, and also the donor organizations such as the World Bank, and the Islamic Development Bank. Currently, the only Sea Forum within the Persian Gulf area is the Regional Organization for Protection of Marine Environment (ROPME), which has made considerable attempts towards the protection and management of the Persian Gulf region. The ROPME has eight member states: Saudi Arabia, Qatar, Bahrain, UAE, Iraq, Oman, Kuwait, and the Islamic Republic of Iran; at the same time the ROPME SEA Area (RSA) is consisted of the Sea of Oman, the Persian Gulf, and the Omanis south eastern coasts located at the vicinity of the Arabian Sea. Thus, ROPME could be considered as one of the most appropriate alternatives for later corporations within the region. The key procedures for determining the first priority regional actions with considerable long- and short-term outcomes for sustainable conservation and use, are regional review of pollution topics pertaining to the Persian Gulf region, such as the root reasons, immediate reasons, impacts and symptoms, analysis of the environmental issues of the region, threats evaluation and severity and scale on the basis of a series of national reports.

\section{Conclusion}

In the present study, the Persian Gulf sea marginal systems from different locations along Iran were selected for Heavy Metals, PAHs and plastic source identification and risk evaluation. The levels of Heavy Metals, PAHS and plastics in the Persian Gulf sea sediments are much higher than their background values, which suggests the involvement of anthropogenic emissions. The concentrations of pollutants in different regions are consistent with local key industries and industrialization levels.

The result suggested that the pollutants in the most study areas were not contaminated-weakly contaminated, but was contaminated-heavily contaminated in some pollution hot spots. It requires local governments to formulate more effective policies and regulations to protect the marine environment. Gouvernements also should set 'zero tolerance for this issue and compel the industries to use biodegradable materials such as starch instead of nondegradable material. This biodegradable material will then be decomposed by microorganisms and ultimately reducing the lifetime of these plastics in the surroundings. In industries, the process of recycling or upgrading of plastic litter should be encouraged.

\section{References}

1. N. Niamaimandi, Z. Bahmyari, N. Sheykhsagha, E. Kouhgardi, and R. G. Vaghei, Reg. Stud. Mar. Sci. 15, 26 (2017)

2. A. Ranjbar Jafarabadi, A. Riyahi Bakhtiari, L. Hedouin, A. Shadmehri Toosi, and T. Cappello, Ecotoxicol. Environ. Saf. 163, 307 (2018)

3. U. NATIONS, G. O. E. O. G. NAMES, and Twenty-third, Historical, Geographical and Legal Validity of the Name: PERSIAN GULF (Vienna, 2006)

4. C. R. C. Sheppard, Mar. Pollut. Bull. 27, 3 (1993)

5. M. S. Massoud, F. Al-Abdali, A. N. AlGhadban, and M. Al-Sarawi, Environ. Pollut. 93, 271 (1996)

6. R. Michael Reynolds, Mar. Pollut. Bull. 27, 35 (1993)

7. I. M. Madany, A. A. A. Wahab, and Z. AlAlawi, Water. Air. Soil Pollut. 91, 233 (1996)

8. S. De Mora, S. W. Fowler, E. Wyse, and S. Azemard, Mar. Pollut. Bull. 49, 410 (2004)

9. C. Sheppard, M. Al-Husiani, F. Al-Jamali, F. Al-Yamani, R. Baldwin, J. Bishop, F. Benzoni, E. Dutrieux, N. K. Dulvy, S. R. V. Durvasula, D. A. Jones, R. Loughland, D. Medio, M. 
Nithyanandan, G. M. Pilling, I. Polikarpov, A. R. G. Price, S. Purkis, B. Riegl, M. Saburova, K. S. Namin, O. Taylor, S. Wilson, and K. Zainal, Mar. Pollut. Bull. 60, 13 (2010)

10. I. Al-Saleh, I. Al-Doush, and A. EcheverriaQuevedo, Bull. Environ. Contam. Toxicol. 63, 451 (1999)

11. A. R. G. Price, C. R. C. Sheppard, and C. M. Roberts, Mar. Pollut. Bull. 27, 9 (1993)

12. AGEDI, (2016)

13. T. W. Kureishy, Mar. Pollut. Bull. 27, 183 (1993)

14. P. Literathy, Mar. Pollut. Bull. 27, 349 (1993)

15. S. de Mora, I. Tolosa, S. W. Fowler, J. P. Villeneuve, R. Cassi, and C. Cattini, Mar. Pollut. Bull. 60, 2323 (2010)

16. A. Ranjbar Jafarabadi, A. R. Bakhtiari, Z. Yaghoobi, C. K. Yap, M. Maisano, and T. Cappello, Chemosphere (2018)

17. I. Tolosa, S. J. De Mora, S. W. Fowler, J. P. Villeneuve, J. Bartocci, and C. Cattini, Mar. Pollut. Bull. 50, 1619 (2005)

18. A. Ranjbar Jafarabadi, A. Riyahi Bakhtiari, M. Maisano, P. Pereira, and T. Cappello, Sci. Total Environ. 640-641, 1500 (2018)

19. A. Ranjbar Jafarabadi, A. Riyahi Bakhtiari, N. Spanò, and T. Cappello, Mar. Pollut. Bull. 137, 185 (2018)

20. Y. Fakhri, N. Saha, A. Miri, M. Baghaei, L. Roomiani, M. Ghaderpoori, M. Taghavi, H. Keramati, Z. Bahmani, B. Moradi, A. Bay, and R. H. Pouya, Food Chem. Toxicol. 118, 348 (2018)

21. S. Dobaradaran, T. C. Schmidt, I. Nabipour, N. Khajeahmadi, S. Tajbakhsh, R. Saeedi, M. Javad Mohammadi, M. Keshtkar, M. Khorsand, and F. Faraji Ghasemi, Waste Manag. 78, 649 (2018)

22. A. Naji, M. Nuri, and A. D. Vethaak, Environ. Pollut. 235, 113 (2018) 